\title{
Kanalizasyon Sistemlerinin Diferansiyel Evrim Algoritması Kullanılarak Optimum Tasarımı
}

\author{
Erhan TAN ${ }^{1}$ \\ Derya SADAK ${ }^{2}$ \\ M. Tamer AYVAZ
}

ÖZ

$\mathrm{Bu}$ çalışmada kanalizasyon sistemlerinin optimum tasarımının yapılabildiği diferansiyel evrim (DE) optimizasyon tekniğine dayanan bir çözüm yaklaşımı geliştirilmiştir. Geliştirilen yaklaşımda her bir boruya ait eğim değeri optimizasyon modelinde karar değişkeni olarak kullanılmakta ve bu değerler için toplam sistem maliyeti minimize edilecek şekilde belirlenen piyasa çapları içerisinden boru çapları seçilmektedir. Optimizasyon işlemi esnasında sağlanması gereken fiziksel ve yönetimsel kısıtların tümü penaltı fonksiyonu yaklaşımı kullanılarak optimizasyon modeline dahil edilmiştir. Geliştirilen yaklaşımın performansı iki örnek sistem üzerinde test edilmiş ve literatürde verilenlere benzer veya daha iyi sonuçlar elde edilmiştir.

Anahtar Kelimeler: Kanalizasyon sistemi, optimum tasarım, optimizasyon.

\section{ABSTRACT \\ Optimum Design of Sewer Systems by using Differential Evolution Algorithm}

In this study, a solution approach which is based on the differential evolution (DE) optimization method is developed for optimum design of the sewer systems. In the developed approach, the slope of each pipe is used as the decision variable of the optimization model and the diameters are selected from the available diameters in market for minimizing the total system cost. All the physical and managerial constraints to be satisfied during the optimization process is included to the model by using the penalty function approach. The

\footnotetext{
Not: Bu yazı

- Yayın Kurulu’na 18 Mart 2019 günü ulaşmıştır. 17 Eylül 2019 günü yayımlanmak üzere kabul edilmiştir.

- 30 Kasım 2020 gününe kadar tartışmaya açıktır.

- https://dx.doi.org/10.18400/tekderg.541507

1 Pamukkale Üniversitesi, Fen Bilimleri Enstitüsü, İnşaat Mühendisliği ABD, Denizli erhan091@hotmail.com - https://orcid.org/0000-0003-4326-8982

2 Sakarya Üniversitesi, İnşaat Mühendisliği Bölümü, Sakarya - deryasadak@sakarya.edu.tr https://orcid.org/0000-0001-5306-9253

3 Pamukkale Üniversitesi, İnşaat Mühendisliği Bölümü, Denizli - tayvaz@pamukkale.edu.tr https://orcid.org/0000-0002-8566-2825
} 
performance of the proposed approach is tested on two example systems and similar or better results are obtained compared to the obtained results given in literature.

Keywords: Sewer system, optimum design, optimization.

\section{GíRiș}

Kanalizasyon sistemlerinin minimum maliyetli tasarımı son yıllarda geçerliliğini koruyan önemli bir mühendislik problemidir. Bu sistemlerin kurulum maliyetindeki ufak bir düşüş, ekonomik anlamda büyük miktarda tasarruf edilmesine karşılık gelmektedir. Bu nedenden dolayı kanalizasyon sistemlerinin ilk yatırım maliyetinin hidrolik ve işletme kısıtlarına bağlı olarak minimize edilmesi literatürde dikkate alınan önemli optimizasyon problemleri arasında yer almaktadır. Bu optimizasyon probleminin çözülebilmesi için öncelikle sistemin kurulacağı yerleşim yerine ait imar planı ve arazi topoğrafyası incelenerek kanalizasyon sisteminin geçeceği güzergah ile akış yönleri belirlenmekte ve hidrolik tasarım aşamasına geçilmektedir. Belirlenen kriterler doğrultusunda kurulan hidrolik model ardından kullanılacak optimizasyon modeline entegre edilerek farklı karar değişkeni değerleri için sistemin hidrolik açıdan verdiği tepki belirlenebilmektedir. Bu noktada dikkat edilmesi gereken önemli noktalardan biri optimizasyon modeli kapsamında karar değişkeni olarak kullanılacak ve sistem yatırım maliyetini etkileyen faktörlerin doğru bir şekilde belirlenmesidir. $\mathrm{Bu}$ kapsamda sistem maliyetini etkileyen ana faktörler boru çapları ve eğimleridir. Literatürde boru çap ve eğimlerinin karar değişkeni olarak seçilmesinde aşağıdaki üç durumla karşılaşılmaktadır [1]: i) karar değişkeni olarak boru çaplarının kullanılması; ii) karar değişkeni olarak boru eğimlerinin kullanılması; iii) karar değişkeni olarak hem boru çaplarının hem de boru eğimlerinin kullanılması. Birinci durumun seçilmesi halinde her bir borunun çapı optimizasyon modeli tarafından belirlenmektedir. Bu durumda boru eğimleri mevcut debi ve enkesit bilgilerinin Manning denklemine konulması ile dolaylı olarak belirlenebilmektedir. İkinci durumda ise karar değişkeni olarak boru eğimleri kullanılmakta ve boru çapları yine Manning denklemi yardımıyla belirlenebilmektedir. Bu aşamada piyasada bulunan boru çapları ile tasarım yapılması gerektiğinden dolayı problemin çözümü boru eğimleri bakımından sürekli, boru çapları bakımından ise kesikli olmaktadır. Üçüncü durumda ise hem boru çapları hem de boru eğimleri optimizasyon modelinde karar değişkenleri olarak kullanılmakta olup en genel durum için çözüm bu durumda elde edilmektedir. Ancak karar değişkeni sayısının artması ile matematiksel çözüm uzayının büyümesi çözüme ulaşmayı güçleştirmektedir [1].

Bu noktada dikkat edilmesi gereken diğer bir önemli husus ise her üç durum için belirlenen değişken değerleri için boru çap ve eğimlerinin birbiri ile sıkı bir etkileşim halinde olduğudur. Örnek olarak boru eğiminin arttırılması aynı debinin daha küçük çaplı bir boru ile iletilmesine imkan sağlarken kazı maliyetinin artmasına neden olmaktadır. Boru eğimlerinin azaltılması durumunda ise tam tersi olarak daha büyük çaplı ve dolayısıyla daha maliyetli boruların kullanılması gerekmektedir. Bu kapsamda bu değişkenler arasındaki en uygun dengenin (trade-off) optimizasyon modelleri kullanılarak belirlenmesi büyük önem taşımaktadır.

Yukarıda verilen 3 farklı durum için literatürde yapılan çalışmalar incelendiğinde ilgili problemin çözümünün hem doğrusal [2-3] hem de doğrusal olmayan [4-5] programlamaya dayanan çözüm yaklaşımları kullanılarak yapılmış olduğu görülmektedir. Ancak genel anlamda kanalizasyon sistemlerindeki boruların seri bağlı yapılarından dolayı ilgili 
optimizasyon probleminin çözümünde dinamik programlamaya dayanan çözüm yaklaşımları yaygın olarak kullanılmıştır [6-10]. Bu yaklaşımlar genel olarak kanalizasyon sistemleri gibi seri bağlı sistemlere kolayca uygulanabilir olduğu halde sürekli ve ayrık yapıdaki karar değişkenlerinin aynı anda bulunduğu problemlerin çözümünün zor oluşu, hidrolik kısıtlarının sağlanmasındaki güçlük ve lokal optimum çözümlere yakalanma riskinin yüksek oluşu gibi nedenlerden dolayı her durumda optimum olarak çözülemeyebilmektedir [11]. Bu nedenle sezgisel optimizasyon tekniklerinin kanalizasyon sistemlerinin optimum tasarımında kullanımı yaygınlık kazanmıştır. Sezgisel optimizasyon teknikleri genel olarak doğada karşılaşılan süreçlerin matematiksel benzeşiminin optimizasyon problemlerinin çözümüne uyarlanmasını esas almaktadır. Geleneksel optimizasyon teknikleri ile karşılaştırıldıklarında sezgisel optimizasyon tekniklerinin en büyük avantajı birden çok aday çözüm ile özel bir başlangıç çözümüne gerek duyulmadan global optimum veya global optimuma yakın çözümlerin elde edilebilmesidir. Bu yöntemler ile ayrıca matematiksel çözüm uzayının sürekli ve içbükey-dışbükey olmaması durumlarında da optimum çözüme ulaşabilmektedir [12].

Literatürde kanalizasyon sistemlerinin optimum tasarım probleminin çözümünde sezgisel optimizasyon tekniklerinin kullanıldığı farklı çözüm yaklaşımları bulunmaktadır. Bu çözüm yaklaşımları çözülen problemler bakımından farklılıklar gösterse de genel olarak aralarındaki temel fark kullanılan optimizasyon tekniklerinin farklılığından kaynaklanmaktadır. İlgili problemin çözümünde literatürde yaygın olarak genetik algoritma (GA) [1, 13-17], parçacık sürü optimizasyon tekniği (PSO) [18-21], karınca kolonisi optimizasyonu (KKO) [22-27], tavlama benzetimi (TB) [11, 28-29], tabu arama (TA) [11, 30-31] gibi optimizasyon teknikleri kullanılmış olmasına rağmen diferansiyel evrim (DE) optimizasyon tekniğinin kullanıldığı çalışma sayısı oldukça kısıtlıdır. Bu kapsamda yazarlar tarafından ulaşılabilen tek çalışma Liu ve diğ. [32] tarafından gerçekleştirilmiştir. İlgili çalışma kapsamında kanalizasyon sistemlerinin optimum tasarımı amacıyla yeni bir DE yaklaşımı önerilmiş ve karar değişkeni olarak kesikli yapıdaki boru çapları kullanılarak iki örnek uygulama çözülmüştür. Bu çalışma kapsamında ise Liu ve diğ. [32]'de yapılandan farklı olarak ilgili problemin DE ile çözümü aşamasında karar değişkeni olarak boru eğimleri kullanılmış ve belirlenen eğim değerleri için uygun boru çapları tanımlanan boru çapı kümesi içerisinden seçilmiştir. Bu sayede ilgili optimizasyon problemi sürekli bir çözüm uzayı üzerinde çözülmüştür. Çözüm aşamasında gerekli hidrolik ve işletme kısıtlarının tümü ceza fonksiyonu yaklaşımı ile amaç fonksiyonuna dahil edilmiştir. Geliştirilen çözüm yaklaşımının performansı literatürde verilen iki örnek sistem üzerinde farklı çözüm parametreleri ve rastgele sayı üreteçleri kullanılarak test edilmiştir. Elde edilen sonuçlar DE tabanlı çözüm yaklaşımı ile literatürde farklı yaklaşımlar kullanılarak belirlenenlerle uyumlu sonuçlar elde edilebileceğini göstermiştir.

\section{MODEL GELIŞTİIILMESI}

Önceki bölümde belirtildiği gibi bu çalışma kapsamında kanalizasyon sistemlerinin optimum tasarım problemi DE tabanlı bir çözüm yaklaşımı kullanılarak çözülmüştür. Bu işlemin yapılabilmesi için öncelikle ilgili problemin hidrolik ve işletme kısıtları dikkate alınarak formüle edilmesi gerekmektedir. Aşağıda öncelikle bu formülasyon verilmiş ve ardından DE optimizasyon tekniği ile sistem maliyeti minimum olacak şekilde optimum tasarımın nasıl yapıldığı konusunda bilgi verilmiştir. 


\subsection{Kanalizasyon Sistem Optimizasyonu}

Kanalizasyon sistemlerinin optimum tasarımı problemi genel anlamda aşağıdaki amaç fonksiyonu ve kısıtlar kullanılarak ifade edilmektedir [1]:

$\Phi=\min \left\{\sum_{k=1}^{N} \mathcal{F}\left(d_{k}, L_{k}, \bar{Z}_{k}\right)\right\}$

Kisitlar:

$g_{k, 1}: q_{k} \geq Q_{k}^{*}$

$g_{k, 2}: V_{k} \leq V_{\max }$

$g_{k, 3}: V_{k} \geq V_{\min }$

$g_{k, 4}: \frac{y_{k}}{d_{k}} \leq \alpha$

$g_{k, 5}: S_{k} \geq S_{\min }$

$g_{k, 6}: E_{k}^{u} \leq E_{\max }$

$g_{k, 7}: \quad E_{k}^{u} \geq E_{\min }$

$g_{k, 8}: \quad E_{k}^{d} \leq E_{\max }$

$g_{k, 9}: \quad E_{k}^{d} \geq E_{\min }$

burada $\Phi$, amaç fonksiyonu değerini; $N$, sistemdeki boru sayısını; $d_{k}, k$ nolu borunun çapını; $L_{k}, k$ nolu borunun uzunluğunu; $\bar{Z}_{k}, k$ nolu borunun yerleştirilmesi için gerekli ortalama kazı derinliğini; $\mathcal{F}(\bullet)$, boru çap, uzunluk ve kazı giderlerini dikkate alarak hesaplanan toplam sistem maliyetini; $q_{k}, k$ nolu boruda normal derinlik oluşturacak akım debisini; $Q_{k}^{*}, k$ nolu boru için kullanılan tasarım debisini; $V_{k}, k$ nolu borudaki akış hızını; $V_{\min }$ ve $V_{\max }, k$ nolu boru için tanımlanmış minimum ve maksimum akış hızlarını; $y_{k}, k$ nolu borudaki su yüksekliğini; $\alpha$, tüm borular için müsaade edilebilir maksimum doluluk oranını; $S_{k}, k$ nolu borunun eğimini; $S_{\min }$, tüm borular için tanımlanan minimum taban eğimini; $E_{k}^{u}$ ve $E_{k}^{d}, k$ nolu borunun sırasıyla başlangıç ve bitiş noktaları üzerindeki dolgu kalınlığını; $E_{\min }$ ve $E_{\max }$ ise tüm borular için müsaade edilebilir minimum ve maksimum dolgu kalınlıklarını göstermektedir. Verilen bu büyüklükler detaylı olarak Şekil 1 üzerinde gösterilmiştir.

Yukarıda verilen kısıtlardan $g_{k, 1}$, borular içindeki akım debisinin proje debisine eşit veya büyük olması; $g_{k, 2}$ ve $g_{k, 3}$, borular içindeki akım hızının yönetmeliklerde verilen minimum ve maksimum hız şartlarını sağlaması; $g_{k, 4}$, borular içinde serbest yüzeyli akım profilinin sağlanması; $g_{k, 5}$, borular için minimum taban eğimi koşulunun sağlanması; $E_{\min }$ ve $E_{\max }$ ise borular üzerindeki dolgu kalınlıklarının yönetmeliklerde verilen minimum ve maksimum değerler arasında kalmasını sağlamak amacıyla tanımlanmıştır. Bu noktada dikkat edilmesi 
gereken önemli bir husus Denklem (1) ile (10) arasında verilen matematiksel formülasyonun basitleştirilmiş kanalizasyon sistemleri için tanımlanmış olduğudur. Daha genel bir problemin çözümünde tek bir tasarım debisi kullanmak yerine bu debinin zamanla değişimini gösteren hidrografin modele girdi olarak verilmesi ve problemin zamanla değişen akım durumları için çözülmesi gerekmektedir. Ayrıca pompa gibi ilave ekipmanların da modelleme aşamasına dahil edilmesi gerekmektedir.

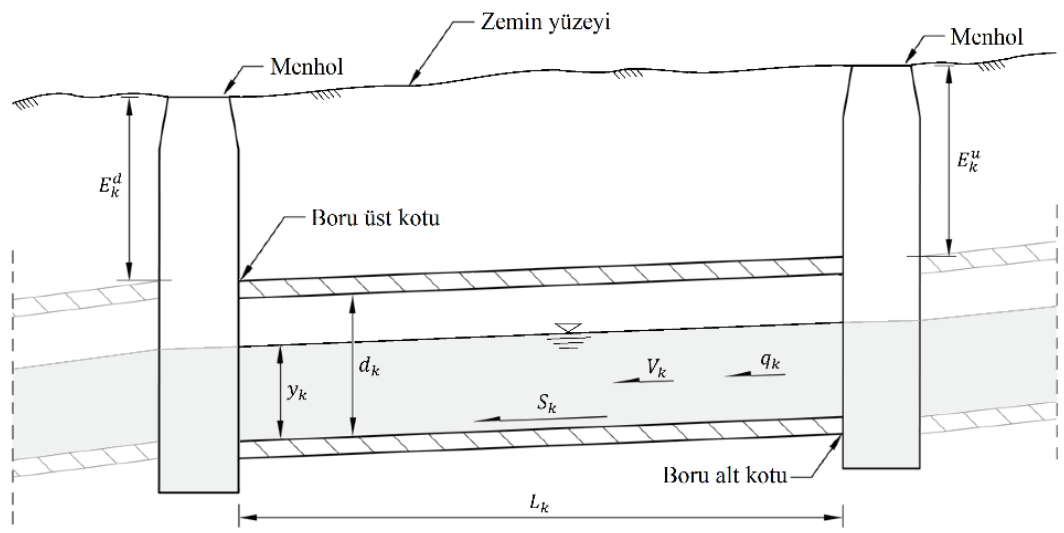

Şekil 1 - Genel akış boykesiti

\subsection{Diferansiyel Evrim (DE) Optimizasyon Tekniği}

$\mathrm{Bu}$ çalışma kapsamında kanalizasyon sistemlerinin optimum tasarım probleminin çözümü DE tabanlı bir optimizasyon modeli ile yapılmıştır. DE ilk olarak Storn ve Price [33] tarafından geliştirilmiş evrimsel tabanlı bir sezgisel optimizasyon tekniğidir. Genel işleyiş ve hesaplama mantığı bakımından GA ile büyük benzerlikler taşımasına rağmen DE'nin GA'dan en büyük farkı ilgili problemin ikilik sayı dizileri yerine onluk sayı dizileri ile kodlanarak çözülebilmesidir. GA'da kullanılan mutasyon, çaprazlama ve seçim operatörleri DE'de de kullanılmasına rağmen, GA'dan farklı olarak popülasyondaki tüm bireyler (kromozom) bu operatörler tarafindan işlem görmektedir [34]. Bu amaçla her bir birey, rastgele olarak seçilen başka üç bireye sırasıyla mutasyon ve çaprazlama operatörü uygulanarak elde edilen yeni birey ile karşılaştırılmakta ve amaç fonksiyonu değerleri bakımından daha iyi olan birey seçim operatörü kullanılarak bir sonraki jenerasyona aktarılmaktadır. Bu işlemin verilen durma koşulu sağlanıncaya kadar uygulanmasıyla global optimum bakımından etkin sonuçlar elde edilebilmektedir. Diğer sezgisel optimizasyon teknikleri ile karşılaştırıldığında DE'nin en büyük avantajları lokal optimum çözümlere yakalanma olasılığının düşük olması ve programlanabilirliğinin kolay olmasıdır. Matematiksel olarak DE ile bir optimizasyon probleminin çözümü aşağıdaki hesap adımlarına göre yapılmaktadır:

$p$ popülasyondaki birey (çözüm vektörü) sayısını, $n$ karar değişkeni sayısını, $G$ jenerasyon indisini, $\boldsymbol{x}_{i, G}=\left[x_{i, G}^{1}, x_{i, G}^{2}, x_{i, G}^{3}, \cdots, x_{i, G}^{n}\right](i=1,2,3, \cdots, p)$ optimizasyon modeli tarafindan belirlenecek $n$ boyutlu çözüm vektörünü, $\boldsymbol{x}_{\min }=\left\{x_{\min }^{1}, x_{\min }^{2}, x_{\min }^{3}, \cdots, x_{\min }^{n}\right\}$ ve $\boldsymbol{x}_{\max }=$ $\left\{x_{\max }^{1}, x_{\max }^{2}, x_{\max }^{3}, \cdots, x_{\max }^{n}\right\}$ sırasıyla karar değişkenlerinin alt ve üst sınırlarını gösteren çözüm vektörlerini göstermek üzere popülasyon içindeki $i$ nolu aday çözüme ait $j$ nolu karar 
değişkeninin $G=0$ nolu jenerasyondaki başlangıç değeri aşağıdaki eşitliğe bağlı olarak üretilmektedir [33]:

$x_{i, 0}^{j}=x_{\min }^{j}+r(0,1) \times\left(x_{\max }^{j}-x_{\min }^{j}\right)$

burada $r(0,1)$ değeri 0 ile 1 arasında değişen üniform dağılıma sahip rastgele sayıyı göstermektedir. Bu aşamadan sonra, DE kapsamındaki mutasyon operatörü kullanılarak yeni bir mutant vektörü $\boldsymbol{v}_{i, G}=\left[v_{i, G}^{1}, v_{i, G}^{2}, v_{i, G}^{3}, \cdots, v_{i, G}^{n}\right](i=1,2,3, \cdots, p)$ oluşturulmaktadır. Bu noktada dikkat edilmesi gereken önemli hususlardan biri mutant vektörü oluşturma aşamasında literatürde önerilmiş olan farklı mutasyon stratejilerinin olduğudur. $\mathrm{Bu}$ stratejilerden "DE/rand/1" stratejisine göre mutant vektör $\boldsymbol{v}_{i, G}$ aşağıdaki eşitliğe bağlı olarak üretilmektedir [33]:

$\boldsymbol{v}_{i, G}=\boldsymbol{x}_{r_{1}^{i}, G}+F\left(\boldsymbol{x}_{r_{2}^{i}, G}-\boldsymbol{x}_{r_{3}^{i}, G}\right)$

burada $F$ mutasyon işleminin etkisinin kontrol edildiği ölçek katsayısını, $r_{k}^{i}(k=1,2,3)$ ise $[1, p]$ kapalı aralığında birbirinden ve $i$ değerinden farklı olarak üretilmiş rastgele tamsayıları göstermektedir. $\mathrm{Bu}$ aşamanın ardından yeni çözüm vektörü $\boldsymbol{u}_{i, G}=\left[u_{i, G}^{1}, u_{i, G}^{2}, u_{i, G}^{3}, \cdots, u_{i, G}^{n}\right]$ $(i=1,2,3, \cdots, p)$ çaprazlama operatörü kullanılarak aşağıdaki şekilde üretilmektedir [33]:

$u_{i, G}^{j}= \begin{cases}v_{i, G}^{j}, & \text { eğer } r_{j}(0,1) \leq C_{r} \text { veya } j=j_{\text {rand }} \\ x_{i, G}^{j}, & \text { aksi halde }\end{cases}$

burada $C_{r}$ çaprazlama oranını, $j_{\text {rand }}$ ise $[1, n]$ kapalı aralığında rastgele olarak üretilmiş üniform dağılıma sahip tamsayıyı göstermektedir. Görüleceği gibi, $r_{j}(0,1) \leq C_{r}$ veya $j=$ $j_{\text {rand }}(j=1,2,3, \cdots, n)$ koşullarından herhangi birinin sağlanması durumunda $\boldsymbol{u}_{i, G}$ vektörünün $j$ nolu bileşeni $\boldsymbol{v}_{i, G}$ vektöründen, aksi halde ise $\boldsymbol{x}_{i, G}$ vektöründen seçilmektedir. Burada $j=j_{\text {rand }}$ koşulu en az bir tane değerin üretilen yeni kromozomdan seçilmesini garanti etmek amaciyla konulmuştur [34]. Literatürde mutasyon işleminde olduğu gibi önerilmiş pek çok çaprazlama stratejisi mevcuttur. Bu stratejiler hakkında detaylı bilgi [35][37]'de verilmiştir. Çaprazlama işleminin ardından yeni jenerasyona aktarılacak aday çözümler seçim operatörü ile aşağıdaki gibi belirlenmektedir [33]:

$\boldsymbol{x}_{i, G+1}=\left\{\begin{array}{l}\boldsymbol{u}_{i, G}, \text { eğer } f\left(\boldsymbol{u}_{i, G}\right) \leq f\left(\boldsymbol{x}_{i, G}\right) \\ \boldsymbol{x}_{i, G}, \text { aksi halde }\end{array}\right.$

burada $f(\bullet)$ ilgili çözüm için hesaplanan amaç fonksiyonu değerini göstermektedir. Denklem (14)'den görüleceği gibi amaç fonksiyonu değeri bakımından daha iyi olan çözüm bir sonraki jenerasyona aktarılmak üzere seçilmektedir. Yukarıda verilen hesap şeması takip edilerek yeni jenerasyona ait tüm aday çözümlerin seçimi yapıldıktan sonra, Denklem (12) ile (14) arasındaki işlemler tanımlanan durma koşulu sağlanıncaya kadar tekrar edilmektedir. Bu çalışma kapsamında durma koşulu olarak maksimum jenerasyon sayısı $\left(G_{\max }\right)$ şartının sağlanması seçilmiştir. 


\subsection{Problem Formülasyonu}

Kanalizasyon sistemlerinin minimum maliyetli olacak şekilde optimum tasarımı problemi matematiksel olarak bir optimizasyon modeli kullanılarak çözülebilmektedir. Bu noktada dikkat edilmesi gereken önemli noktalardan biri Denklem (1)'in optimizasyonu aşamasında Denklem (2) ile (10) arasında verilen kısıtların sağlanması gerektiğidir. Diğer sezgisel algoritmalar gibi DE'de kısıtsız optimizasyon problemlerinin çözümünü yapabildiği için Denklem (1) ile (10) arasinda verilen kısitlı optimizasyon probleminin kisitsız hale dönüştürülmesi gerekmektedir. Bu amaçla ilgili kısıtlar ceza fonksiyonu yaklaşımı ile optimizasyon sürecine dahil edilmiştir. Genel olarak kısıtlı bir optimizasyon probleminin ceza fonksiyonu yaklaşımı ile ifade edilmiş hali aşağıdaki gibi olmaktadır:

$\Phi^{\prime}=\min \left\{\Phi+\sum_{k=1}^{N} \lambda \cdot P\left(\boldsymbol{g}_{k}\right)\right\}$

burada $\Phi^{\prime}$, ceza fonksiyonu eklenmiş amaç fonksiyonu değerini; $\boldsymbol{g}_{k}=$ $\left[g_{k, 1}, g_{k, 2}, g_{k, 3}, \cdots, g_{k, 9}\right](k=1,2,3, \cdots, N)$, Denklem (2) ile (10) arasında verilen kisitların saklandığ 1 kısıt vektörünü; $P(\bullet)$, kısıt ihlali kapsamında ilgili ceza değerinin hesaplanmasında kullanılan ceza fonksiyonunu; $\lambda=\left[\lambda_{1}, \lambda_{2}, \lambda_{3}, \cdots, \lambda_{9}\right]$ ise Denklem (2) ile (10) arasında verilen kısıtlar için tanımlanmış olan ceza parametrelerini göstermektedir. $\mathrm{Bu}$ noktada dikkat edilmesi gereken önemli noktalardan biri ceza fonksiyonlarının modele entegre edilmesinde kullanılan $\boldsymbol{\lambda}$ parametre değerlerinin seçimidir. Genel olarak probleme bağlı olarak seçilen bu değerler ne kadar büyük alınırsa, ilgili koşulun sağlanması için harcanacak çaba o derece fazla olmaktadır [38]. Literatürde verilen koşulların sağlanabilmesi amacıyla önerilmiş farklı ceza fonksiyonu yapıları bulunmaktadır. Bu çalışma kapsamında yapılan kısıt ihlalinin karelerinin ceza olarak kullanıldığı aşağıdaki amaç fonksiyonu ve normalize edilmiş kısıt yapıları kullanılmıştır:

$\Phi^{\prime}=\min \left\{\sum_{k=1}^{N} \mathcal{F}\left(d_{k}, L_{k}, \bar{Z}_{k}\right)+\sum_{l=1}^{9} \lambda_{l} \sum_{k=1}^{N}\left(\hat{g}_{k, l}\right)^{2}\right\}$

Kisitlar:

$\hat{g}_{k, 1}:\left(1-\frac{q_{k}}{Q_{k}^{*}}\right) \leq 0$

$\hat{g}_{k, 2}:\left(\frac{V_{k}}{V_{\max }}-1\right) \leq 0$

$\hat{g}_{k, 3}:\left(1-\frac{V_{k}}{V_{\min }}\right) \leq 0$ 
$\hat{g}_{k, 4}:\left(\frac{y_{k}}{\alpha \cdot d_{k}}-1\right) \leq 0$

$\hat{g}_{k, 5}:\left(1-\frac{S_{k}}{S_{\min }}\right) \leq 0$

$\hat{g}_{k, 6}:\left(\frac{E_{k}^{u}}{E_{\max }}-1\right) \leq 0$

$\hat{g}_{k, 7}:\left(1-\frac{E_{k}^{u}}{E_{\min }}\right) \leq 0$

$\hat{g}_{k, 8}:\left(\frac{E_{k}^{d}}{E_{\max }}-1\right) \leq 0$

$\hat{g}_{k, 9}:\left(1-\frac{E_{k}^{d}}{E_{\min }}\right) \leq 0$

burada $\hat{g}_{k, l}(k=1,2,3, \cdots, N ; l=1,2,3, \cdots, 9)$, Denklem (2) ile (10) arasında verilmiş olan kısıtların normalleştirilmiş hallerini göstermektedir. Geliştirilen çözüm yaklaşımı ile Denklem (16) ile (25) arasında verilen problemin DE ile çözülmesi sonucunda kanalizasyon sistemlerinin optimum tasarım problemi çözülebilmektedir.

\section{SAYISAL UYGULAMALAR}

Geliştirilen çözüm yaklaşımın performansı literatürde verilmiş iki örnek uygulama üzerinde test edilmiştir. Bu uygulamalar MATLAB ortamında hazırlanan DE tabanlı optimizasyon modeline Denklem (16) ile (25) arasında verilen optimizasyon formülasyonunun entegre edilmesiyle çözülmüştür. Önceki bölümde belirtilmiş olduğu gibi problemle alakalı tüm kısıtlar ilgili amaç fonksiyonuna ceza fonksiyonları ile entegre edilmiştir. Bu noktada dikkat edilmesi gereken en önemli husus bu entegrasyon aşamasında ceza parametrelerinin ne alınması gerektiğidir. Daha önceden belirtildiği gibi bu parametreler genellikle probleme bağlı olduğu için çözüme başlanmadan önce denemeler yapılarak nihai değerler belirlenmiştir. Yapılan denemeler sonucunda bu değerlerin tümü $\lambda_{1-9}=10^{9}$ olarak alınmıştır. Diğer bir önemli nokta ise DE tabanlı optimizasyon modelinde kullanılan parametre değerlerinin ve üretilen rastgele sayılara ait çekirdek (seed) değerlerinin seçimidir. Her ne kadar DE'nin global optimum ya da global optimuma yakın sonuçlar bulmadaki performansının yüksek olduğu bilinse de algoritmanın performansının farklı çözüm 
parametreleri ve rastgele sayı çekirdekleri kullanılarak test edilmesi gerekmektedir. $\mathrm{Bu}$ kapsamda ilgili uygulamalar iki senaryo dikkate alınarak çözülmüştür. Senaryo A'da farklı DE çözüm parametreleri kullanılarak çözüm işlemi yapılmıştır. $\mathrm{Bu}$ kapsamda $p \in$ $[20,30,40,50], C_{r} \in[0.20,0.40,0.60,0.80]$ ve $F \in[0.20,0.40,0.60,0.80]$ alınmış ve bu parametre değerlerinin birbirine göre değişiminin dikkate alındığ $14^{3}=64$ farklı parametre kombinasyonu için problem çözülmüştür. Senaryo A kapsamında kullanılan 64 parametre kombinasyonu için çözüm parametrelerinin değişimi Şekil 2'de verilmiştir. Yapılan bu çözümler sonucunda minimum amaç fonksiyonu değerini veren parametre seti problemin çözümünde kullanılmıştır.

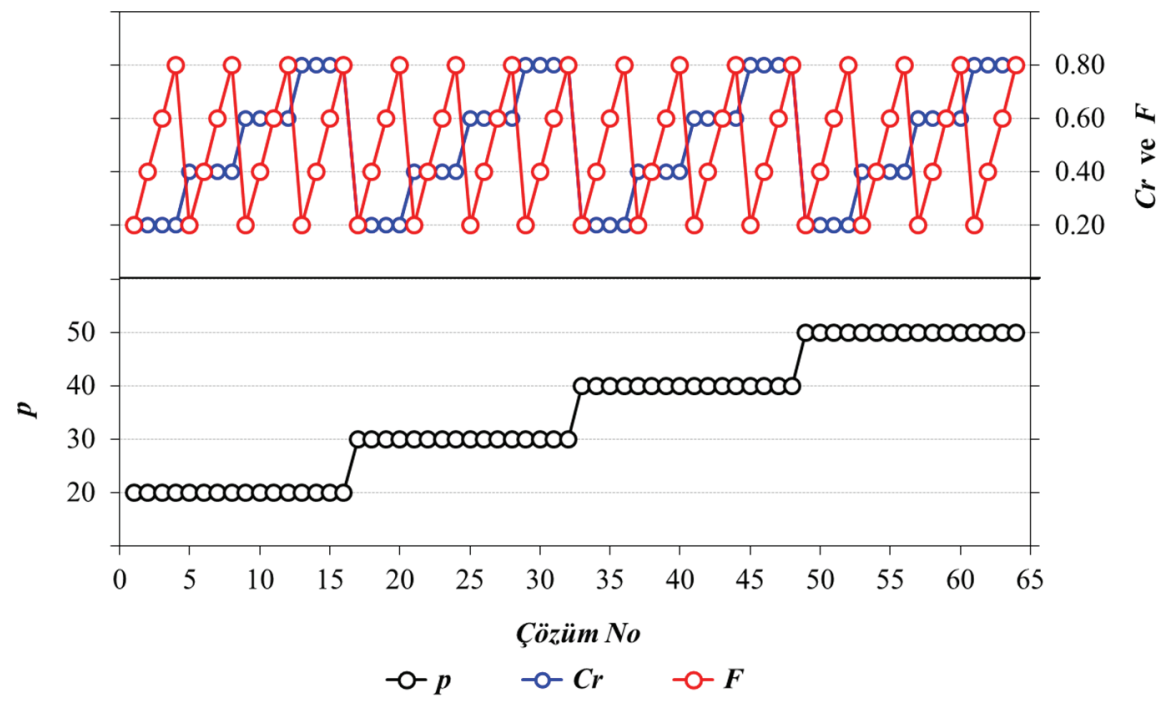

Şekil 2 - Senaryo A kapsamında kullanılan farklı DE çözüm parametrelerini içeren parametre kombinasyonlart

Senaryo A için 64 farklı parametre seti arasından minimum amaç fonksiyonu değerini veren kombinasyonun belirlenmesinin ardından Senaryo B kapsamında her iki örnek uygulamanın performansı farklı rastgele sayı üreteçleri için değerlendirilmiştir. Bu bağlamda 10 farklı çekirdek değeri için her iki problem çözülmüş ve geliştirilen yaklaşımın performansının rastgele sayılara ne oranda bağlı olduğu detaylı olarak değerlendirilmiştir. Senaryo A ve B kapsamında erken yakınsama probleminin önüne geçmek amacıyla durma koşulu 500,000 amaç fonksiyonu hesaplanması şeklinde alınmış ve bu kapsamda maksimum jenerasyon sayısı $G_{\max }=500,000 / p$ olarak modele girilmiştir.

\subsection{Uygulama 1}

$\mathrm{Bu}$ bölümde geliştirilen modelin performansı ilk olarak Mays ve Wenzel [6] tarafından tasarlanan ve daha sonra pek çok araştırmacı tarafından kullanılan örnek bir sistem üzerinde test edilmiştir. Şekil 3'den görüleceği gibi kanalizasyon sistemi 21 düğüm noktası ve toplam uzunluğu yaklaşık $2.6 \mathrm{~km}$ olan 20 borudan oluşmaktadır. Sistem ile ilgili karakteristik 
özellikler Çizelge 1'de sunulmuştur. Problemin çözümü aşamasında dikkate alınan minimum ve maksimum hız değerleri sırasıyla $0.6 \mathrm{~m} / \mathrm{s}$ ve $3.6 \mathrm{~m} / \mathrm{s}$ olarak alınmış olup tüm borular içindeki akış hızının bu aralık içinde olması gerekmektedir. Benzer şekilde tüm borular için müsaade edilebilir minimum ve maksimum dolgu kalınlıkları sırasıyla $2.4 \mathrm{~m}$ ve $6.0 \mathrm{~m}$ olarak alınmış olup dolgu kalınlıklarının model tarafından bu aralıkta belirlenmesi gerekmektedir.

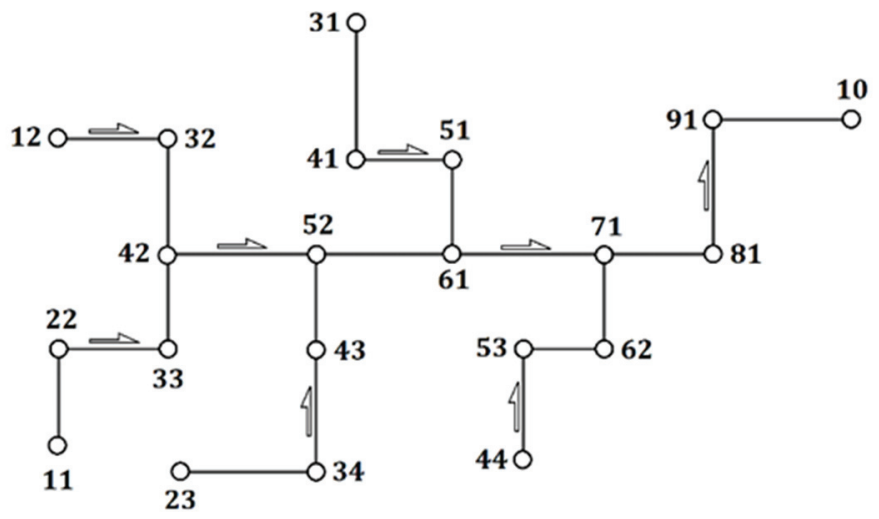

Şekil 3 - Uygulama l'e ait boru ve düğüm nokta planı

Çizelge 1 - Uygulama 1'e ait karakteristik özellikler

\begin{tabular}{|c|c|c|c|c|}
\hline \multirow{2}{*}{ Boru } & \multicolumn{2}{|c|}{ Zemin Kotu $(\mathrm{m})$} & $\begin{array}{c}L \\
(\mathrm{~m})\end{array}$ & $\begin{array}{c}Q^{*} \\
\left(\mathrm{~m}^{3} / \mathrm{s}\right)\end{array}$ \\
\cline { 2 - 3 } $11-22$ & Memba & Mansap & 106.68 & 0.1132 \\
$22-33$ & 152.40 & 150.88 & 121.92 & 0.1982 \\
$33-42$ & 150.88 & 148.49 & 106.68 & 0.2548 \\
$12-32$ & 148.49 & 146.30 & 121.92 & 0.1132 \\
$32-42$ & 149.35 & 147.83 & 131.08 & 0.2265 \\
$42-52$ & 147.83 & 146.30 & 167.68 & 0.6229 \\
$23-34$ & 146.30 & 143.26 & 147.64 & 0.2265 \\
$34-43$ & 149.35 & 147.83 & 137.16 & 0.3398 \\
$43-52$ & 147.83 & 144.78 & 106.68 & 0.4530 \\
$52-61$ & 144.78 & 143.26 & 152.40 & 1.2459 \\
$31-41$ & 143.26 & 141.73 & 152.40 & 0.2548 \\
$41-51$ & 147.83 & 144.78 & 106.68 & 0.4530 \\
$51-61$ & 144.78 & 143.26 & 106.68 & 0.5663 \\
$61-71$ & 143.26 & 141.73 & 172.21 & 2.0104 \\
$44-53$ & 141.73 & 138.65 & 121.92 & 0.1132 \\
$53-62$ & 142.65 & 141.43 & 91.44 & 0.1699 \\
$62-71$ & 141.43 & 140.21 & 105.23 & 0.2548 \\
$71-81$ & 140.21 & 138.65 & 121.92 & 2.4635 \\
$81-91$ & 138.65 & 137.46 & 152.40 & 2.5201 \\
$91-10$ & 137.46 & 136.55 & 186.54 & 2.6617 \\
\hline
\end{tabular}


$\mathrm{Bu}$ uygulamanın çözümünü Mays ve Wenzel [6] ilk olarak diferansiyel dinamik programlamaya dayanan bir optimizasyon yaklaşımı ile yapmış ardından ilgili problemin çözümü pek çok araştırmacı tarafından farklı çözüm yaklaşımları kullanılarak yapılmıştır [1, 3, 6-8, 22, 40]. Bu çözümlerin tümünde amaç fonksiyonunun hesaplanması aşamasında Meredith [39] tarafından verilmiş olan aşağıdaki eşitlik kullanılmıştır:

$$
\begin{aligned}
& C_{p}= \begin{cases}10.98 d+0.80 H-5.98 & ; \quad H<10 \\
5.94 d+1.17 H+0.50 H d-9.64 ; & d \leq 3, H \geq 10 \\
30.00 d+4.90 H-105.90 & ; d>3\end{cases} \\
& C_{m}=250+h^{2}
\end{aligned}
$$

burada $C_{p}$, boru maliyet terimini $(\$ / \mathrm{ft}) ; C_{m}$, menhol maliyet terimini $(\$) ; d$, boru çapını ( $\left.\mathrm{ft}\right)$; $H$, ortalama boru alt kot derinliği (ft); $h$ ise menhol derinliğini (ft) ifade etmektedir. Buradan yola çıkarak kanalizasyon sistemi için toplam maliyet (Denklem (1)) tüm borular için hesaplanan $C_{p}$ ve $C_{m}$ değerlerinin toplamına eşit kabul edilmiş olup DE tabanlı optimizasyon yaklaşımı ile bu maliyeti minimum yapan sistem tasarımının belirlenmesi amaçlanmıştır. Daha önceden belirtildiği gibi her bir boruya ait eğim değeri $\left(S_{k} ; k=1,2,3, \cdots, 20\right)$ optimizasyon modelinde karar değişkeni olarak kullanılmıştır. Çözüm aşamasında tüm borular için Manning yüzey pürüzlülüğü $n=0.013$ ve müsaade edilebilir maksimum doluluk oranı $\alpha=0.82$ olarak alınmış olup bu değerler ilgili örneğin çözüldüğü diğer çalışmalardan alınmıştır. Belirlenen eğim değerleri için boru çapları piyasada bulunabilen şu çaplar arasından seçilmiştir: $304.8 \mathrm{~mm}$ (12 inç), $381.0 \mathrm{~mm}$ (15 inç), $457.2 \mathrm{~mm}$ (18 inç), 533.4 $\mathrm{mm}$ (21 inç), $762 \mathrm{~mm}$ (30 inç), $914.4 \mathrm{~mm}$ (36 inç), $1066.8 \mathrm{~mm}$ (42 inç) ve $1219.2 \mathrm{~mm}$ (48 inç). $\mathrm{Bu}$ seçim, optimizasyon modeli tarafından her bir boruya ait eğim değerinin belirlenmesinin ardından Denklem (3) ve (5)'de verilen kısıtlar sağlanacak şekilde yukarıda verilen çapların küçükten büyüğe doğru teker teker denenmesi suretiyle yapılmaktadır. $\mathrm{Bu}$ aşamanın ardından ilgili problem Senaryo A için çalıştırılmış ve her bir çözüm için Şekil 4'de verilen yakınsama grafikleri elde edilmiştir.

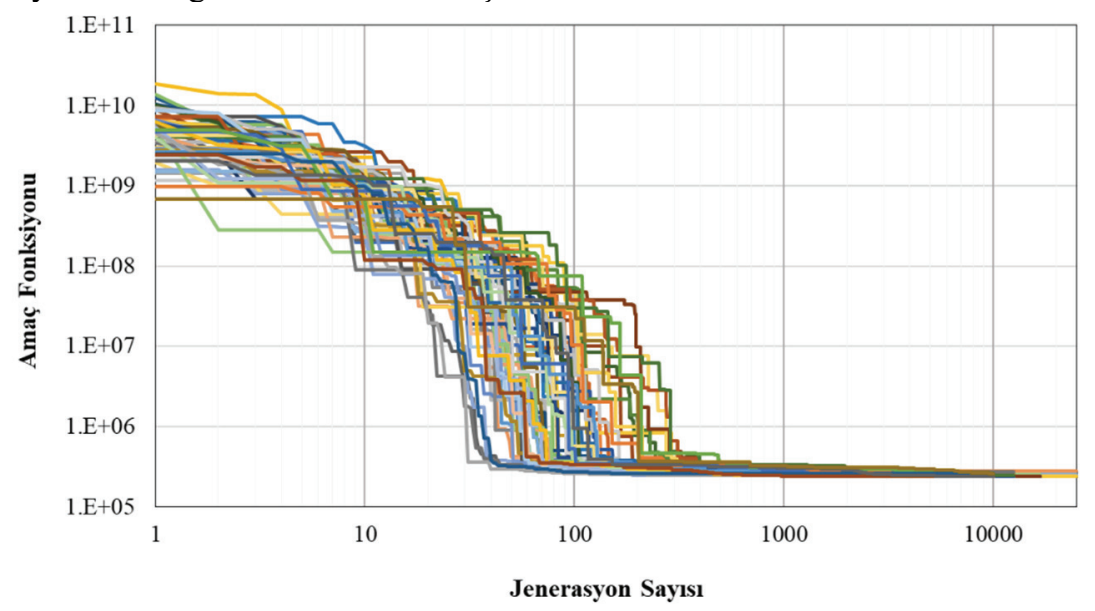

Şekil 4 - Uygulama 1 'in Senaryo A kapsamında 64 farklı parametre seti için çözülmesi sonucu elde edilen yakınsama grafikleri 
Şekil 4'den görüleceği gibi tüm çözümler farklı başlangıç noktalarından başlamakta olup yaklaşık olarak benzer mertebedeki sonuçlara yakınsamaktadır. Genel olarak çözümlere ait yakınsama davranışı değerlendirildiğinde başlangıç jenerasyonlarında kısıtların sağlanmadığı ve bunun sonucunda da amaç fonksiyonu değerleri üzerinde yüksek ceza değerleri bulunduğu açıkça görülmektedir. Farklı DE çözüm parametreleri için yapılan 64 çözümün istatistiksel değerlendirmesi Çizelge 2'de sunulmuştur:

Çizelge 2 - Uygulama 1 için Senaryo A ve B kapsamında elde edilen sonuçların istatistiksel değerlendirmesi

\begin{tabular}{|l|c|c|}
\hline \multirow{2}{*}{} & \multicolumn{2}{|c|}{ Toplam Maliyet (ABD \$) } \\
\cline { 2 - 3 } & Senaryo A & Senaryo B \\
\hline Çözüm Sayıs1 & 64 & 10 \\
En Küçük & 239,961 & 239,961 \\
En Büyük & 279,367 & 239,979 \\
Ortalama & 244,682 & 239,964 \\
Standart Sapma & 8,389 & 6 \\
\hline
\end{tabular}

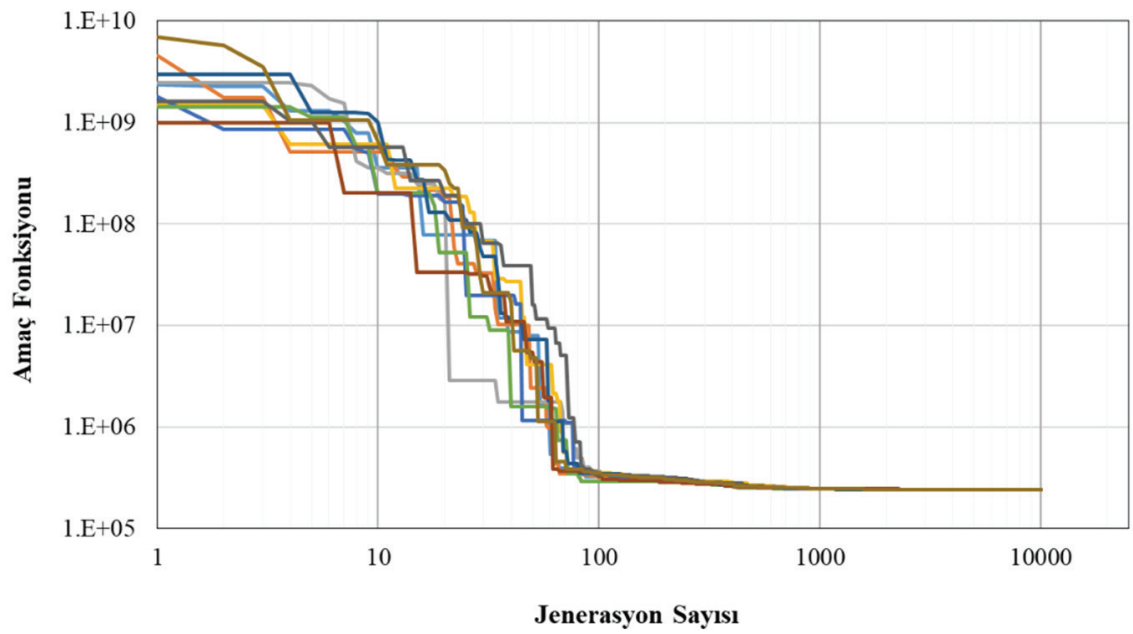

Şekil 5 - Uygulama 1'in Senaryo B kapsamında farklı rastgele sayı üreteçleri için çözülmesi sonucu elde edilen yakınsama grafikleri

Çizelge 2'den görüleceği gibi Senaryo A kapsamında yapılan 64 çözüm için şebekenin toplam maliyeti en küçük 239,961 \$, en büyük 279,367 \$, ortalama 244,682 \$ olarak belirlenmiştir. Yapılan çözümler ortalama etrafinda 8,389 \$'lık bir standart sapma ile dağılım göstermektedir. Elde edilen bu sonuçlar değerlendirildiğinde en küçük amaç fonksiyonu değerinin $p=50, C_{r}=0.60$ ve $F=0.40$ parametre değerleri ile elde edildiği görülmüştür. 
$\mathrm{Bu}$ aşamanın ardından belirlenen parametre değerleri kullanılarak Senaryo B kapsamında ilgili problem 10 farklı rastgele sayı üreteci için tekrar çözülmüştür. Yapılan bu 10 çözüme ait yakınsama grafikleri Şekil 5'de verilmiştir. Görüleceği gibi tüm çözümler farklı başlangıç noktalarından başlamış ve mertebe olarak aynı amaç fonksiyonu değerine yakınsamıştır. Senaryo B kapsamında elde edilen bu sonuçların istatistiksel değerlendirmesi ise yine Çizelge 2'de verilmiştir. Görüleceği gibi en küçük ve en büyük sistem maliyeti sırasıyla 239,961 \$ ve 239,979 \$ olarak elde edilmiş olup yapılan 10 çözüm için standart sapma değeri 6 \$ olarak elde edilmiştir. Bu sonuç geliştirilen DE tabanlı optimizasyon yaklaşımı ile başlangıç çözümlerine çok fazla bağlı kalmadan aynı mertebede sonuçlara ulaşılabileceğini göstermiştir. Senaryo B sonucunda elde edilen en küçük sistem maliyeti için (239,961 \$) optimizasyon modeli tarafından belirlenen sistem karakteristikleri Çizelge 3'de verilmiştir.

Çizelge 3 - Uygulama 1 için optimizasyon modeli tarafindan belirlenen karakteristikler

\begin{tabular}{|c|c|c|c|c|c|c|}
\hline \multirow{2}{*}{ Boru } & Eğim & Çap & H1z & Doluluk Oranı & \multicolumn{2}{|c|}{ Dolgu Kalınlıları } \\
\cline { 2 - 7 } & $S_{k}(\mathrm{~m} / \mathrm{m})$ & $d_{k}(\mathrm{~mm})$ & $V_{k}(\mathrm{~m} / \mathrm{s})$ & $y_{k} / d_{k}(\mathrm{~m} / \mathrm{m})$ & $E_{k}^{u}(\mathrm{~m})$ & $E_{k}^{d}(\mathrm{~m})$ \\
\hline $11-22$ & 0.0142 & 304.8 & 1.88 & 0.77 & 2.40 & 2.40 \\
$22-33$ & 0.0196 & 381.0 & 2.47 & 0.66 & 2.40 & 2.40 \\
$33-42$ & 0.0205 & 381.0 & 2.62 & 0.80 & 2.40 & 2.40 \\
$12-32$ & 0.0126 & 304.8 & 1.77 & 0.82 & 2.40 & 2.42 \\
$32-42$ & 0.0116 & 457.2 & 2.10 & 0.63 & 2.42 & 2.40 \\
$42-52$ & 0.0193 & 533.4 & 3.18 & 0.82 & 2.40 & 2.59 \\
$23-34$ & 0.0153 & 381.0 & 2.26 & 0.82 & 2.40 & 3.14 \\
$34-43$ & 0.0168 & 457.2 & 2.65 & 0.73 & 3.14 & 2.40 \\
$43-52$ & 0.0142 & 533.4 & 2.68 & 0.71 & 2.40 & 2.40 \\
$52-61$ & 0.0115 & 762.0 & 3.11 & 0.82 & 2.40 & 2.62 \\
$31-41$ & 0.0200 & 381.0 & 2.59 & 0.80 & 2.40 & 2.40 \\
$41-51$ & 0.0142 & 533.4 & 2.68 & 0.71 & 2.40 & 2.40 \\
$51-61$ & 0.0237 & 533.4 & 3.43 & 0.69 & 2.40 & 3.40 \\
$61-71$ & 0.0121 & 914.4 & 3.60 & 0.80 & 3.40 & 2.40 \\
$44-53$ & 0.0126 & 304.8 & 1.77 & 0.82 & 2.40 & 2.72 \\
$53-62$ & 0.0099 & 381.0 & 1.82 & 0.77 & 2.72 & 2.40 \\
$62-71$ & 0.0148 & 457.2 & 2.38 & 0.62 & 2.40 & 2.40 \\
$71-81$ & 0.0098 & 1066.8 & 3.54 & 0.73 & 2.40 & 2.40 \\
$81-91$ & 0.0078 & 1066.8 & 3.21 & 0.82 & 2.40 & 2.68 \\
$91-10$ & 0.0087 & 1066.8 & 3.39 & 0.82 & 2.68 & 3.40 \\
\hline
\end{tabular}

Çizelge 3'den görüleceği gibi, optimizasyon modeli tarafından belirlenen eğim değerleri için hesaplanan hız, doluluk oranı ve dolgu kalınlıkları kısıtlarının tümü sağlanmıştır. Her bir boru için çap değeri ise daha önceden tanımlanan piyasa borularına ait kesikli çözüm kümesi 
içerisinden tanımlanan koşullar yardımıyla seçilmiştir. Daha önceden belirtildiği gibi bu uygulama literatürde farklı çözüm yaklaşımları kullanılarak da çözülmüştür. $\mathrm{Bu}$ çalışma kapsamında elde edilen sistem maliyetinin literatürde verilenlerle karşılaştırılması Çizelge 4'de verilmiştir.

Çizelge 4 - Uygulama 1 için elde edilen sonuçların sistem maliyeti ve fonksiyon hesaplama sayısı bakımından karşılaştırılması

\begin{tabular}{|l|c|c|}
\hline & Toplam Maliyet (ABD \$) & Fonksiyon Hesaplama Sayıs1 \\
\hline Mays and Wenzel [6] & 265,775 & - \\
Robinson and Labadie [7] & 275,218 & - \\
Miles and Heaney [40] & 245,874 & - \\
Afshar [22] & 241,496 & 29,900 \\
Afshar [1] & 241,896 & 100,000 \\
\hline & 248,008 & 29,900 \\
Mevcut çalışma & 240,860 & 100,000 \\
& 239,961 & 420,450 \\
\hline
\end{tabular}

Çizelge 4'den görüleceği gibi geliştirilen yaklaşım kullanılarak elde edilen sistem maliyeti $(239,961$ \$) gerek deterministik gerek sezgisel tabanlı çözüm yaklaşımlarından daha düşük olarak elde edilmiştir. Bu noktada model performanslarının karşılaştırılmasında dikkat edilecek en önemli husus amaç fonksiyonunun kaç kez hesaplanması sonucu bu sonuçlara ulaşıldığgdır. Daha önceden belirtildiği gibi geliştirilen yaklaşım kapsamında ilgili problemin çözümü 500,000 amaç fonksiyonu hesabı için yapılmış olup Çizelge 4'de verilen en iyi çözüm (239,961 \$) ilgili amaç fonksiyonu değerinin 420,450 defa çalıştırılması sonucu elde edilmiştir. Literatürde verilen sonuçlar incelendiğinde ilgili problem Afshar [22] tarafından karınca kolonisi optimizasyon tekniği iyileştirilerek çözülmüş ve 29,900 çözüm sonrasında sstem maliyeti 241,496 \$ olarak elde edilmiştir. Benzer şekilde Afshar [1] tarafından genetik algoritma tabanlı bir optimizasyon yaklaşımı revize edilerek ilgili problem çözülmüş ve olarak 100,000 amaç fonksiyonu çözümü sonrasında toplam sistem maliyeti 241,896 \$ olarak bulunmuştur. $\mathrm{Bu}$ kapsamda karşılaştırma amacıyla geliştirilen yaklaşımın 29,900 ve 100,000'nci amaç fonksiyonu hesabın sonucu elde edilen sistem maliyetleri de Çizelge 4'de sunulmuştur. Görüleceği gibi 29,900'ncü çözüm sonrası elde edilen sistem maliyeti (248,008 \$) Afshar [22] tarafından elde edilen sonuçtan (241,496 \$) daha büyüktür. Buna karşın, 100,000 'ncü çözüm sonrası elde edilen sistem maliyeti $(240,860$ \$) ise Afshar [1] tarafından elde edilen sistem maliyetinden $(241,896$ \$) daha düşüktür. Bu sonuçlar geliştirilen DE tabanlı çözüm yaklaşımı ile literatürde verilenlerle uyumlu ve/veya daha iyi sonuçlar elde edilebileceğini göstermiştir.

\subsection{Uygulama 2}

Bu uygulama kapsamında Afshar ve diğ. [41] tarafından kullanılan ve İran'ın Kirman şehrinde bulunan örnek bir sistem çözülmüştür. Yerleşim planı Şekil 6'da verilen sistemde 
21 adet düğüm noktası ve toplam uzunluğu $7.62 \mathrm{~km}$ olan 20 adet boru bulunmaktadır. Sistem ile ilgili karakteristik özellikler Çizelge 5'de sunulmuştur. $\mathrm{Bu}$ uygulama için çözüm aşamasında dikkate alınan minimum ve maksimum hız değerleri sırasıyla $0.3 \mathrm{~m} / \mathrm{s}$ ve $3.0 \mathrm{~m} / \mathrm{s}$ olarak alınmıştır. Benzer şekilde tüm borular için müsaade edilebilir minimum ve maksimum dolgu kalınlıkları sırasıyla $2.45 \mathrm{~m}$ ve $6.0 \mathrm{~m}$ olarak alınmıştır. Tüm borular için Manning yüzey pürüzlülüğü $n=0.013$ ve maksimum doluluk oranı $\alpha=0.82$ olarak alınmıştır. Karar değişkeni olarak belirlenen boru eğimleri için boru çapları şu çaplar arasından seçilmiştir: $150 \mathrm{~mm}, 200 \mathrm{~mm}, 250 \mathrm{~mm}, 300 \mathrm{~mm}, 400 \mathrm{~mm}, 500 \mathrm{~mm}, 600 \mathrm{~mm}, 700 \mathrm{~mm}$.

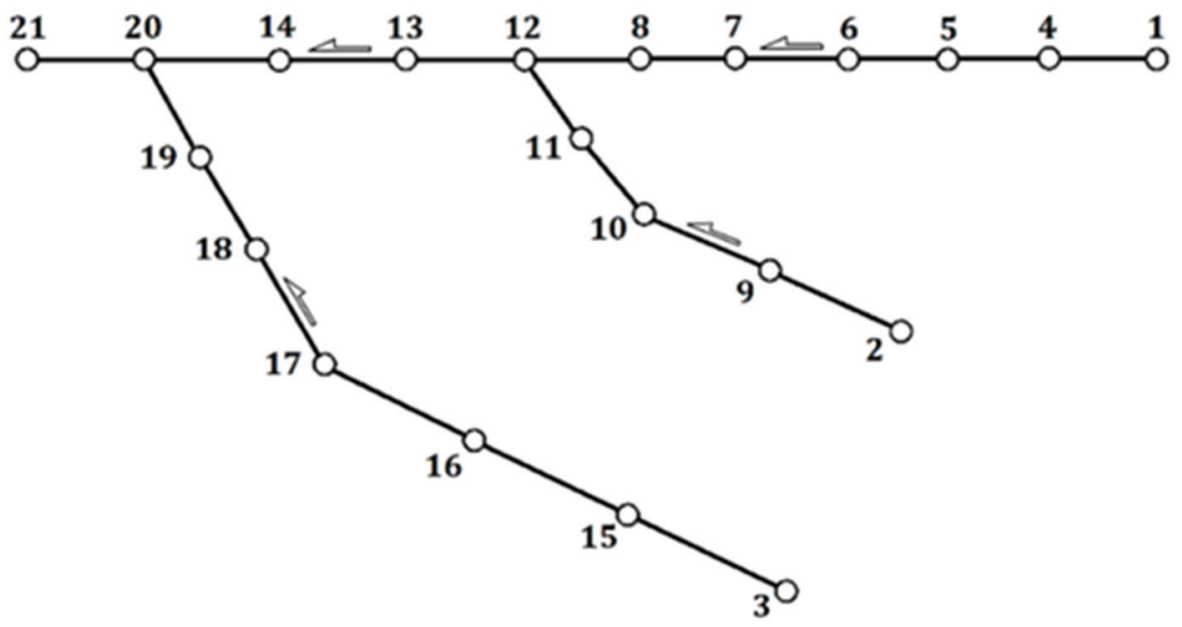

Şekil 6 - Uygulama 2'ye ait boru ve düğüm nokta planı

$\mathrm{Bu}$ uygulama kapsamında amaç fonksiyonunun hesaplanabilmesi ve literatürde verilen sonuçlarla karşılaştırma yapılabilmesi amacıyla Afshar ve diğ. [41] tarafindan verilen aşağıdaki sistem maliyet fonksiyonu kullanılmıştır:

$$
\begin{aligned}
& C_{p}=1.93 e^{3.43 d}+0.812 H^{1.53}+0.437 d H^{1.47} \\
& C_{m}=41.46 h
\end{aligned}
$$

burada $C_{p}$, boru maliyet terimini $(\$ / \mathrm{m}) ; C_{m}$, menhol maliyet terimini $(\$) ; d$, boru çapını $(\mathrm{m})$; $H$, ortalama boru alt kot derinliği $(\mathrm{m}) ; h$ ise menhol derinliğini $(\mathrm{m})$ ifade etmektedir. $\mathrm{Bu}$ tanımlamalar altında sistem için toplam maliyet $C_{p}$ ve $C_{m}$ değerlerinin toplamına eşit kabul edilmiş olup bu maliyeti minimum yapan sistem tasarımının belirlenmesi amaçlanmıştır. $\mathrm{Bu}$ uygulamanın çözümü de Senaryo A ve B kapsamında farklı DE çözüm parametreleri ve rastgele sayı çekirdek değerleri için yapılmıştır. Senaryo A kapsamında yapılan 64 çözüm için elde edilen yakınsama grafikleri Şekil 7'de sunulmuştur. 
Kanalizasyon Sistemlerinin Diferansiyel Evrim Algoritması Kullanılarak ...

Çizelge 5 - Uygulama 2'ye ait karakteristik özellikler

\begin{tabular}{|c|c|c|c|c|}
\hline \multirow{2}{*}{ Boru } & \multicolumn{2}{|c|}{ Zemin Kotu (m) } & \multirow{2}{*}{$\begin{array}{c}L \\
(\mathrm{~m})\end{array}$} & \multirow{2}{*}{$\begin{array}{c}Q^{*} \\
\left(\mathrm{~m}^{3} / \mathrm{s}\right)\end{array}$} \\
\hline & Memba & Mansap & & \\
\hline $1-4$ & 74.59 & 73.66 & 260 & 0.0279 \\
\hline $2-9$ & 70.70 & 69.90 & 300 & 0.0549 \\
\hline $3-15$ & 73.00 & 71.50 & 400 & 0.0211 \\
\hline $4-5$ & 73.66 & 72.10 & 460 & 0.0304 \\
\hline $5-6$ & 72.10 & 71.19 & 260 & 0.0324 \\
\hline $6-7$ & 71.19 & 69.85 & 300 & 0.0340 \\
\hline $7-8$ & 69.85 & 68.24 & 450 & 0.0366 \\
\hline $8-12$ & 68.24 & 67.28 & 400 & 0.0387 \\
\hline $9-10$ & 69.90 & 69.30 & 270 & 0.0562 \\
\hline $10-11$ & 69.30 & 68.40 & 310 & 0.0580 \\
\hline $11-12$ & 68.40 & 67.28 & 440 & 0.0596 \\
\hline $12-13$ & 67.28 & 66.22 & 470 & 0.0967 \\
\hline $13-14$ & 66.22 & 65.82 & 350 & 0.1012 \\
\hline $14-20$ & 65.82 & 65.42 & 340 & 0.1047 \\
\hline $15-16$ & 71.50 & 70.10 & 400 & 0.0264 \\
\hline $16-17$ & 70.10 & 68.60 & 400 & 0.0300 \\
\hline $17-18$ & 68.60 & 66.80 & 500 & 0.0319 \\
\hline $18-19$ & 66.80 & 66.10 & 400 & 0.0403 \\
\hline $19-20$ & 66.10 & 65.42 & 590 & 0.0446 \\
\hline $20-21$ & 65.42 & 64.50 & 320 & 0.0279 \\
\hline
\end{tabular}

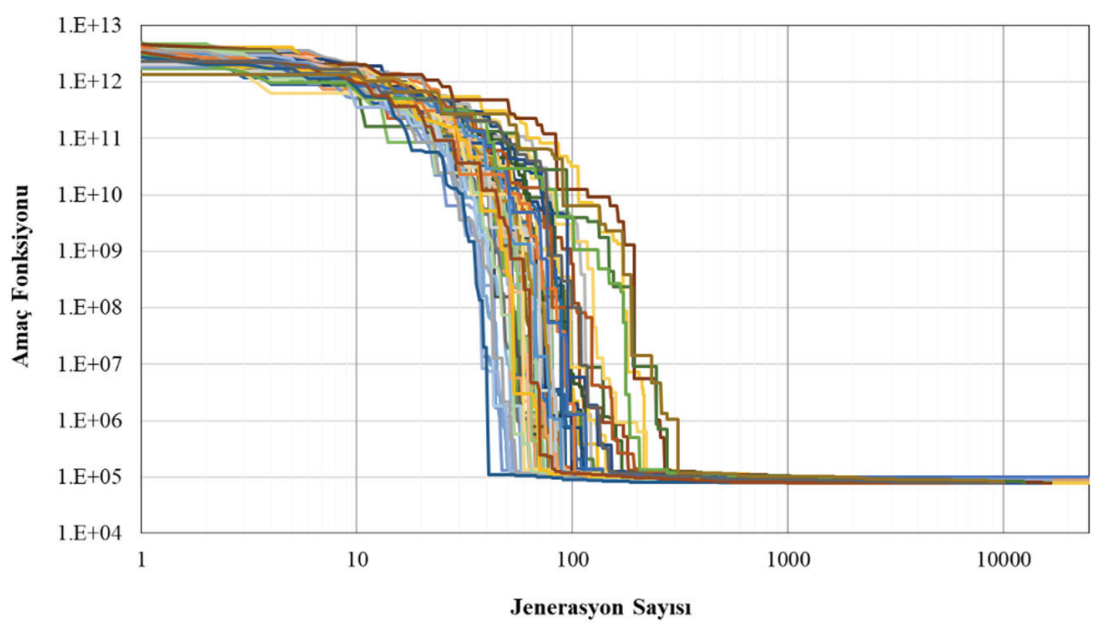

Şekil 7 - Uygulama 2 'nin Senaryo A kapsamında 64 farklı parametre seti için çözülmesi sonucu elde edilen yakınsama grafikleri 
Görüleceği gibi başlangıç aşamasındaki çözümlerin tümü kısıtların sağlanmaması ile alakalı olarak yüksek ceza değerlerine sahiptir. İlerleyen jenerasyonlarda ise kısıtların sağlanmasıyla beraber amaç fonksiyonu değerleri düşmekte ve yaklaşık aynı mertebedeki sonuçlara yakınsamaktadır. Senaryo A kapsamında elde edilen bu çözümlerin istatistiksel değerlendirmesi Çizelge 6'da yapılmıştır. Görüleceği gibi Senaryo A kapsamında yapılan 64 çözüm için sistem maliyeti en küçük 78,699 \$, en büyük 100,751 \$, ortalama 81,097 \$ olarak belirlenmiştir. Yapılan çözümler ortalama etrafinda 3,977 \$'lık bir standart sapma ile dağılım göstermektedir. Belirlenen bu sonuçlar için en küçük amaç fonksiyonu değeri Şekil 2'de verilen parametre kombinasyonlarından $p=30, C_{r}=0.20$ ve $F=0.40$ ile elde edilmiştir. $\mathrm{Bu}$ aşamanın ardından Senaryo B kapsamında ilgili problem 10 farklı rastgele sayı üreteci için tekrar çözülmüştür. Bu çözümlerin tümünde yukarıda belirlenmiş olan DE parametreleri kullanılmıştır. Yapılan bu 10 çözüme ait yakınsama grafikleri Şekil 8'de verilmiştir.

Çizelge 6 - Uygulama 2 için Senaryo A ve B kapsamında elde edilen sonuçların istatistiksel değerlendirmesi

\begin{tabular}{|l|c|c|}
\hline \multirow{2}{*}{} & \multicolumn{2}{|c|}{ Toplam Maliyet (ABD \$) } \\
\cline { 2 - 3 } & Senaryo A & Senaryo B \\
\hline Çözüm Sayıs1 & 64 & 10 \\
En Küçük & 78,699 & 78,694 \\
En Büyük & 100,751 & 78,873 \\
Ortalama & 81,097 & 78,727 \\
Standart Sapma & 3,977 & 54 \\
\hline
\end{tabular}

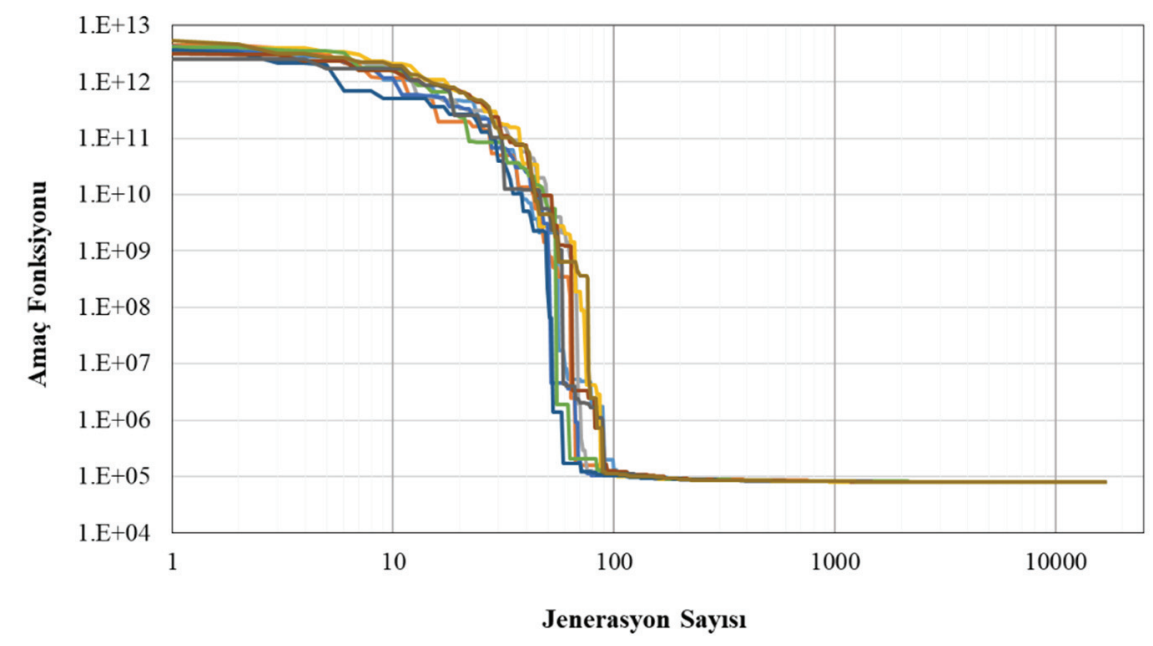

Şekil 8 - Uygulama 2 'nin Senaryo B kapsamında farklı rastgele sayı üreteçleri için çözülmesi sonucu elde edilen yakınsama grafikleri 
Şekil 8'den görüleceği gibi tüm çözümler farklı başlangıç noktalarından başlamış ve mertebe olarak aynı amaç fonksiyonu değerlerine yakınsamıştır. Yapılan bu 10 çözüm için elde edilen sonuçlar da Çizelge 6'da verilmiştir. Görüleceği gibi Senaryo B kapsamında en küçük, en büyük ve ortalama sistem maliyetleri sirasıyla 78,694 \$, 78,873 \$ ve 78,727 \$ olarak elde edilmiştir. Yapılan bu 10 çözüm için standart sapma değeri ise 54 \$ olarak elde edilmiş olup geliştirilen yaklaşım kullanılarak farklı başlangıç çözümleri için yapılan çözümlerin yaklaşık olarak aynı amaç fonksiyonu değerlerine yakınsadığı sonucuna ulaşılmıştır. Senaryo B kapsamında elde edilen en küçük sistem maliyeti için $(78,694$ \$) optimizasyon modeli tarafından belirlenen sistem karakteristikleri Çizelge 7'de verilmiştir.

Çizelge 7 - Uygulama 2 için optimizasyon modeli tarafindan belirlenen karakteristikler

\begin{tabular}{|c|c|c|c|c|c|c|}
\hline \multirow{2}{*}{ Boru } & Ĕ̆im & Çap & H1z & Doluluk Oran1 & \multicolumn{2}{|c|}{ Dolgu Kalınlılar1 } \\
\cline { 2 - 7 } & $S_{k}(\mathrm{~m} / \mathrm{m})$ & $d_{k}(\mathrm{~mm})$ & $V_{k}(\mathrm{~m} / \mathrm{s})$ & $y_{k} / d_{k}(\mathrm{~m} / \mathrm{m})$ & $E_{k}^{u}(\mathrm{~m})$ & $E_{k}^{d}(\mathrm{~m})$ \\
\hline $1-4$ & 0.0036 & 0.25 & 0.80 & 0.67 & 2.45 & 2.45 \\
$2-9$ & 0.0032 & 0.30 & 0.89 & 0.82 & 2.45 & 2.62 \\
$3-15$ & 0.0041 & 0.20 & 0.77 & 0.82 & 2.45 & 2.61 \\
$4-5$ & 0.0034 & 0.25 & 0.80 & 0.73 & 2.45 & 2.45 \\
$5-6$ & 0.0035 & 0.25 & 0.82 & 0.76 & 2.45 & 2.45 \\
$6-7$ & 0.0045 & 0.25 & 0.91 & 0.72 & 2.45 & 2.45 \\
$7-8$ & 0.0038 & 0.25 & 0.85 & 0.82 & 2.45 & 2.54 \\
$8-12$ & 0.0042 & 0.25 & 0.90 & 0.82 & 2.54 & 3.28 \\
$9-10$ & 0.0016 & 0.35 & 0.69 & 0.79 & 2.62 & 2.45 \\
$10-11$ & 0.0036 & 0.30 & 0.94 & 0.82 & 2.45 & 2.67 \\
$11-12$ & 0.0021 & 0.35 & 0.78 & 0.74 & 2.67 & 2.45 \\
$12-13$ & 0.0023 & 0.40 & 0.90 & 0.80 & 2.45 & 2.45 \\
$13-14$ & 0.0024 & 0.40 & 0.92 & 0.82 & 2.45 & 2.88 \\
$14-20$ & 0.0052 & 0.35 & 1.24 & 0.82 & 2.88 & 4.23 \\
$15-16$ & 0.0031 & 0.25 & 0.75 & 0.68 & 2.61 & 2.45 \\
$16-17$ & 0.0037 & 0.25 & 0.83 & 0.69 & 2.45 & 2.45 \\
$17-18$ & 0.0036 & 0.25 & 0.82 & 0.74 & 2.45 & 2.45 \\
$18-19$ & 0.0018 & 0.30 & 0.65 & 0.82 & 2.45 & 2.45 \\
$19-20$ & 0.0012 & 0.35 & 0.58 & 0.74 & 2.45 & 2.45 \\
$20-21$ & 0.0029 & 0.25 & 0.73 & 0.73 & 2.45 & 2.45 \\
\hline
\end{tabular}

Çizelge 7'den görüleceği gibi, belirlenen eğim değerleri için ilgili problem kapsamında hesaplanan hız, doluluk oranı ve dolgu kalınlıkları kısıtlarının tümü sağlanmıştır. Her bir boruya ait çap değerleri ise problem kapsamında tanımlanan kesikli çözüm kümesi içerisinden seçilmiştir. Uygulama 1'de olduğu gibi bu sistemde literatürde farklı çözüm 
yaklaşımları kullanılarak çözülmüştür. Bu kapsamda elde edilen sonuçlar Çizelge 8'de özetlenmiştir.

\section{Çizelge 8 - Uygulama 2 için elde edilen sonuçların sistem maliyeti bakımından karşılaştırılması}

\begin{tabular}{|l|c|}
\hline & Toplam Maliyet (ABD \$) \\
\hline Mansuri ve Khanjani [42] & 83,116 \\
Setoodeh [43] (a) & 82,732 \\
Setoodeh [43] (b) & 81,553 \\
Afshar ve diğ. [41] & 80,879 \\
Mevcut çalışma & 78,694 \\
\hline
\end{tabular}

Çizelge 8'den görüleceği gibi mevcut çalışma için elde edilen sistem maliyeti $(78,694$ \$) literatürde verilen diğer çalışmalardan daha düşüktür. Bu çalışmalar incelendiğinde ilgili problem Mansuri ve Khanjani [42]'da doğrusal olmayan programlama ile, Setoodeh [43] (a)'da Broyden-Fletcher-Goldfarb-Shanno (BFGS) yöntemi ile, Setoodeh [43] (b)'de Fletcher-Reeves yöntemi ile, Afshar ve diğ. [41]'de ise hücresel otomat yöntemi ile çözülmüştür. Geliştirilen yaklaşım ile belirtilen amaç fonksiyonu değerine 417,750 amaç fonksiyonu hesabında ulaşılmış olup bu işlem MATLAB platformunda hazırlanmış bir program kullanılarak Intel Core i7 $2.90 \mathrm{GHz}$ işlemci ve 8.00 GB RAM özelliklerine sahip bir masaüstü bilgisayarda $1145.61 \mathrm{~s}$ zaman almıştır. Elde edilen bu sonuçlar geliştirilen DE tabanlı optimizasyon yaklaşımı ile literatürde verilen deterministik tabanlı optimizasyon yaklaşımlarına göre daha iyi sonuçların makul bilgi-işlem sürelerinde elde edilebileceğini göstermiştir.

\section{SONUÇLAR}

$\mathrm{Bu}$ çalışmada kanalizasyon sistemlerinin optimum tasarımının yapılabildiği DE tabanlı bir optimizasyon yaklaşımı geliştirilmiştir. Geliştirilen yaklaşım kapsamında boru eğimleri karar değişkeni olarak kullanılmış ve belirlenen eğim değerleri için her bir boruya ait çap tanımlanan kesikli çözüm uzayı içerisinden seçilmiştir. Kanalizasyon sistemlerinin tasarımı kapsamında dikkate alınan fiziksel ve yönetimsel kısıtların tümü ilgili kısıtların amaç fonksiyonuna penaltı fonksiyonu yaklaşımı ile entegre edilmesi suretiyle sağlanmıştır. Geliştirilen yaklaşımın performansı literatürde başka çözüm yaklaşımları kullanılarak çözülmüş iki adet örnek uygulama üzerinde test edilmiştir. Bu uygulamaların çözümü farklı DE parametrelerinin ve farklı rastgele sayı üreteçlerinin sonuçlar üzerindeki etkisinin belirlenebildiği iki farklı senaryo için yapılmıştır. Elde edilen sonuçlar DE tabanlı optimizasyon yaklaşımı kullanılarak literatürde verilenlerle uyumlu ve/veya daha iyi sonuçların makul bilgi-işlem sürelerinde elde edilebileceğini göstermiştir. Sonraki çalışma olarak farklı DE mutasyon/çaprazlama stratejileri ve zamanla değişen akım durumları için geliştirilen yaklaşımının genişletilmesi önerilmektedir. 


\section{Teşekkür}

Yazarlar, değerli görüşlerini bildirerek makalenin daha iyi bir formata kavuşmasını sağlayan hakemlere teşekkürlerini sunmaktadır.

\section{Kaynaklar}

[1] Afshar, M. H., Rebirthing Genetic Algorithm for Storm Sewer Network Design. Scientica Iranica Transactions A: Civil Engineering, 19, 1, 11-19, 2012.

[2] Elimam, A. A., Charalambous, C., Ghobrial, F. H., Optimum Design of Large Sewer Networks. Journal of Environmental Engineering, 115, 6, 1171-1190, 1989.

[3] Swamee, P. K., Sharma, A. K., Optimal Design of A Sewer Line Using Linear Programming. Applied Mathematical Modelling, 37, 4430-4439, 2012.

[4] Price, R. K., Design of Storm Water Sewers for Minimum Construction Cost. Proc. 1st International Conference on Urban Strom Drainage, Southampton, United Kingdom, 636-647, 1978.

[5] Swamee, P. K., Design of Sewer Line. Journal of Environmental Engineering, 127, 9, 776-781, 2001.

[6] Mays, L. W., Wenzel, H. G., Optimal Design of Multilevel Branching Sewer Systems. Water Resources Research, 12, 5, 913-917, 1976.

[7] Robinson, D. K., Labadie, J. W., Optimal Design of Urban Storm Water Drainage System. Int. Symposium on Urban Hydrology, Hydraulics and Sediment Control, University of Kentucky, Lexington, KY, USA, 145-156, 1981.

[8] Yen, B. C., Cheng, S. T., Jun, B. H., Voohees, M. L., Wenzel, H. G., Illinois Least Cost Sewer System Design Model, ILSD-1\&2 User's Guide, Dept. of Civil Engineering University of Texas at Austin, USA, 1984.

[9] Kulkarin, V. S., Khanna, P., Pumped Wastewater Collection Systems Optimization. J. of Environmental Engineering, 111, 5, 589-601, 1985.

[10] Li, G., Matthew, R. G. S., New Approach for Optimization of Urban Drainage Systems. Journal of Environmental Engineering, 116, 5, 927-944, 1990.

[11] Yeh, S. F., Chu, C. W., Applying Tabu Search and Simulated Annealing to the Optimal Design of Sewer Networks. Engineering Optimization, 43, 2, 159-174, 2011.

[12] Ayvaz, M. T., A Linked Simulation-Optimization Model for Solving the Unknown Groundwater Pollution Source Identification Problems. Journal of Contaminant Hydrology, 117, 46-59, 2010.

[13] Afshar, M. H., Aplication of A Genetic Algorithm to Storm Sewer Network Optimization. Scientia Iranica, 13, 3, 234-244, 2006.

[14] Haghighi, A., Bakhshipour, A. E., Optimization of Sewer Networks Using an Adaptive Genetic Algorithm. Water Resour Manage, 26, 3441-3456, 2012. 
[15] Afshar, M. H., Afshar, A., Marino, M. A., Darbandi A. A. S., Hydrograph-Based Storm Sewer Design Optimization by Genetic Algorithm. Can. J. Civ. Eng., 33, 3, 319-325, 2006.

[16] Afshar, M. H., Sotoodeh, M. H., Optimal Design of the Sewer Networks with the Genetic Algorithm. J. Eng. Sci. Iran Univ. Sci. Technol, 2, 19, 37-48, 2008.

[17] Çetin, T., Kentsel Yağmur Suyu ve Kanalizasyon Sistemlerinin Optimizasyonu, Doktora tezi, Celal Bayar Üniversitesi-Fen bilimleri Enstitüsü, 2014.

[18] Afshar, M. H., Rebirthing Particle Swarm Optimization Algorithm: Application to Storm Water Network Design. Can. J. Civ. Eng., 35, 10, 1120-1127, 2008.

[19] Izquierdo, J., Montalvo, I., Pérez, R., Fuertes, V. S., Design Optimization of Wastewater Collection Networks by PSO. Comput. Math. Appl., 56, 3, 777-784, 2008.

[20] Nafisi, M., Ahmadi, A., Sewer Networks Optimization by Particle Swarm Optimization with Abilities of Fly-Back Mechanism and Harmony Memory. J. Water Wastewater, 25, 4, 76-87, 2014.

[21] Navin, P. K., Mathur Y. P., Layout and Component Size Optimization of Sewer Network Using Spanning Tree and Modified PSO Algorithm. Water Resour Manage, 30, 10, 3627-3643, 2016.

[22] Afshar, M. H., Improving the Efficiency of Ant Algorithms Using Adaptive Refinement: Application to Storm Water Network Design. Adv. Water. Resour., 29, 9, 1371-1382, 2006.

[23] Afshar, M. H., Partially Constrained Ant Colony Optimization Algorithm for the Solution of Constrained Optimization Problems: Application to Storm Water Network Design. Adv. Water. Resour., 30, 4, 954-965, 2007.

[24] Afshar, M. H., A Parameter Free Continuous Ant Colony Optimization Algorithm for the Optimal Design of Storm Sewer Networks: Constrained and Unconstrained Approach. Adv. Eng. Software, 41, 2, 188-195, 2009.

[25] Moeini, R., Afshar, M. H., Layout and Size Optimization of Sanitary Sewer Network Using Intelligent Ants. Adv. Eng. Software, 51, 49-62, 2012.

[26] Moeini, R., Afshar, M. H., Constrained Ant Colony Optimisation Algorithm for the Layout and Size Optimisation of Sanitary Sewer Networks. Urban Water. J., 10, 3, 154 $173,2013$.

[27] Moeini, R., M. H. Afshar., Arc Based Ant Colony Optimization Algorithm for Optimal Design of Gravitational Sewer Networks. Ain Shams Engineering J., 8, 2, 207-223, 2016.

[28] Karovic, O., Mays L. W., Sewer System Design Using Simulated Annealing in Excel. Water Resour Manage, 28, 13, 4551-4565, 2014.

[29] Kumar, S., Navin, P. K., Mathur, Y.P., Optimization of Sewerage System Using Simulated Annealing. International Journal of Engineering Research \& Technology, 6, 11, 1-6, 2018. 
[30] Liang, L. Y., Thompson, R. G., Young, D. M., Optimizing the Design of Sewer Networks Using Genetic Algorithms and Tabu Search. Eng. Constr. Archit. Manage., 11, 2, 101-112, 2004.

[31] Haghighi, A., Bakhshipour A. E., Deterministic Integrated Optimization Model for Sewage Collection Networks Using Tabu Search. J. Water. Resour. Plann. Manage., 141, 1, 1-11, 2014.

[32] Liu, C., Han, H., Wang C., Qiao, J., An adaptive Differential Evolution Algorithm for Sewer Networks Design, Proceeding of the 11th World Congress on Intelligent Control and Automation Shenyang, China, 2014.

[33] Storn, R., Price, K., Differential Evolution a Simple and Efficient Heuristic for Global Optimization Over Continuous Spaces. J. Global Optim., 11, 341-359, 1997.

[34] Keskintürk, T., Diferansiyel Gelişim Algoritması. İstanbul Ticaret Üniversitesi Fen Bilimleri Dergisi, 5-9, 85-99. 2006.

[35] Mezura-Montes, E., Velazquez-Reyes, J., Coello Coello, C.A., A Comparative Study of Differential Evolution Variants for Global Optimization, Proceedings of the Genetic and Evolutionary Computation Conference (GECCO’06), USA, 2006.

[36] Price, K. V., Storn, R. M., Lampinen, J. A., The Differential Evolution Algorithm, Differential Evolution: A Practical Approach to Global Optimization Natural Computing Series, Springer, Berlin, 2005.

[37] Qin, A. K., Huang, V. L., Suganthan P. N., Differential Evolution Algorithm with Strategy Adaptation for Global Numerical Optimization. IEEE Trans. Evol. Comput., 13, 2, 398-417, 2009.

[38] Ayvaz, M. T., Application of Harmony Search Algorithm to the Solution of Groundwater Management Models. Adv. Water Resour., 32, 6, 916-924, 2009.

[39] Meredith, D.D., Dynamic Programming with Case Study on Planning and Design of Urban Water Facilities, Treatise on Urban Water Systems, Colorado State University, Fort Collins, 1972.

[40] Miles, S. W., Heaney, J. P., Better Than Optimal Method For Designing Drainage Systems. Journal of Water Resources Planning and Management, 114, 5, 477-499, 1988.

[41] Afshar, M. H., Shahidi, M., Rohani, M., Sargolzei, M., Application of Cellular Automata to Sewer Network Optimization Problems. Scientia Iranica Transactions A: Civil Engineering, 18, 3, 304-312, 2011.

[42] Mansuri, M. R., Khanjani, M. J., Optimization of Sewer Networks Using Nonlinear Method. Journal of Water and Wastewater, 30, 20-30, 1999.

[43] Setoodeh, M., Optimal Design of Sewer Networks, M.S. Thesis, Iran University of Science and Technology, 2004. 